\title{
Risk factor analysis of the decrease in gait speed among Japanese older outpatients with polypharmacy
}

\author{
Masataka Deguchi ${ }^{1,2}$, Keigo Nishida ${ }^{3}$, Tomoyuki Enokiya $^{4}$ and Kazuya Ooi ${ }^{2 *}$
}

\begin{abstract}
Background: Both polypharmacy and frailty are critical issues faced by the elderly. The decrease in gait speed is an index of frailty, and it is generally associated with falls and fractures, which are risk factors requiring the need for support or long-term patient care. In this study, we assess the risk factors responsible for the decrease in gait speed in older outpatients with polypharmacy.
\end{abstract}

Methods: Thirty-one persons (13 men, 18 women) aged 65 years or above and regularly taking 5 or more internal medications participated in this study.

Results: Propensity score-adjusted multivariate logistic analysis showed that only number of medications was associated with the risk of decreasing gait speed (odds ratio: 16.00, 95\% confidence interval:1.72-149.00, $p$ value $=0.0149$ ). A negative correlation was found between the number of medications and gait speed. In addition, the gait speed of the calcium channel blocker medication group was significantly slower than that of the non-medication group.

Conclusion: These results suggest that not only the number of medications but also the prescription contents is a risk factor for decrease in gait speed and may serve as indexes to identify patients at high risk of requiring support or long-term care.

Keywords: Older outpatients, Polypharmacy, Gait speed, Prescription contents, Calcium channel blocker, Stratum corneum moisture content

\section{Background}

The percentage of elderly in the Japanese population was estimated to be $28.3 \%$ by April 2019 [1]. Accordingly, the number of older outpatients has remarkably risen owing to the rapid aging of the population as well as the increase in chronic medical conditions such as hypertension, diabetes mellitus, and dyslipidemia that are often accompanied by multiple diseases, resulting in polypharmacy [2]. Polypharmacy leads to not only decreases in patient compliance but also increases in health care costs [3]. Moreover, it has been reported that the concomitant assumption of more than 5 or 6 medications

\footnotetext{
* Correspondence: zooi@suzuka-u.ac.jp

${ }^{2}$ Laboratory of Clinical Pharmacology, Graduate School of Pharmaceutical Sciences, Suzuka University of Medical Science, 3500-3 Minamitamagaki, Suzuka, Mie 513-8670, Japan

Full list of author information is available at the end of the article
}

can lead to risk factors such as falling [4] or adverse drug reactions [5], respectively.

Besides polypharmacy, Fried et al. proposed the concept of frailty as an additional issue in the elderly [6]. In recent years, the importance of frailty has attracted widespread interest to prevent long-term care owing to its pathophysiology and diagnosis [7]. The authors proposed 5 symptoms as the phenotype of frailty: 1 ) weight loss, 2) weakness, 3) exhaustion, 4) slowness, and 5) low activity. In addition, they suggested that if patients showed more than three of these symptoms, they should be deemed as frailty [6]. Other studies have been reported that decreases in gait speed, which is an index of slowness, is associated with falling and fractures [8-11]. For the elderly, these are risk factors requiring the need for support or long-term patient care [12]. Therefore, it can be assumed that the evaluation of the gait speed at 
the community pharmacy settings might lead to health care support for patients.

By identifying a risk factor associated with the decrease in gait speed, it is possible to detect in advance a patient with a high risk of frailty, falls, and fracture. The aim of this study is to assess the risk factors for the decrease in gait speed in older outpatients with polypharmacy.

\section{Methods}

\section{Patient selection}

Between November 2016 and April 2018, 65 years or older outpatients who visited the Heart Pharmacy Zaitaku Center (Matsusaka-city, Mie-Pref.) and regularly took 5 or more internal medications, were enrolled in the study. Patients with gait disturbance were excluded from the study.

\section{Propensity score-adjusted multivariate logistic analysis}

Risk factors for the decrease in gait speed were evaluated by performing a multivariate logistic analysis with an adjusted propensity score. When explaining the instructions indicated on a medication at our pharmacy, we performed a multifaceted listening to older outpatients who appeared to have issues with walking. A tendency of these patients to complain about itchy dry skin was observed. Furthermore, it was reported that a low body mass was associated with increased dry skin manifestations and decreased skin elasticity in communitydwelling older adults [13], thus suggesting that dry skin may be an indicator of frailty. Therefore, in the present study, we selected the stratum corneum moisture content, an indicator of dry skin, as a risk factor candidate. Overall, this analysis identified 8 risk factors for frailty: sex, height, weight, thigh circumference, gait speed, body mass index (BMI), stratum corneum moisture content, and number of medications. Height $(\mathrm{cm})$, weight $(\mathrm{kg})$, and thigh circumference $(\mathrm{cm})$ were measured, and their BMI was calculated using the following formula: $\mathrm{BMI}=$ Weight (kg) / [Height (m) $]^{2}$.

The participants were asked to walk $5 \mathrm{~m}$ in the pharmacy room at their usual pace, and then their gait speed $(\mathrm{m} / \mathrm{s})$ was calculated. The stratum corneum moisture content was measured non-invasively in the forearm of the patients with a portable skin moisture meter (Courage + Khazaka, Germany; HP10-N) by using the electric capacitance method. The resulting measurements were indicated using a relative value ranging from 0 to 99 arbitrary unit (a.u.). The environment of the room where the measurements were conducted was independent of the outside air, and the room temperature was kept within the range between 15 and $25^{\circ} \mathrm{C}$ by using an air conditioner to remove the effect of perspiration. After acclimatization by leaving the forearm exposed from the clothes and standing still for about $15 \mathrm{~min}$, the measurement was performed 3 times for each patient, and the mean value was calculated. The number of medications was calculated by adding the number of internal drug prescription filled for patients of the Heart Pharmacy Zaitaku Center and all other medical institutions, and it was confirmed via a medication record kept by a pharmacist. The medications to be counted were those that have been taken continuously for more than 1 month. This calculation was performed at the time when the gait speed and stratum corneum moisture content were measured. Based on the therapeutic category number [14] of the medicine that each patient was taking, we tabulated and analyzed the number of patients for each therapeutic category.

The participants were divided based on the J-CHS standards, which are the criteria used in the diagnosis of frailty in Japan, into the following two groups: 1 ) fast gait speed group with a gait speed of $\geq 1.0 \mathrm{~m} / \mathrm{s}$ and 2) slow gait speed group with a gait speed of $<1.0 \mathrm{~m} / \mathrm{s}$. The prescription contents for both the fast and slow gait speed group of patients were tabulated. Subsequently, the difference in the proportion of patients belonging to each group was analyzed. Furthermore, the difference in gait speed between the medication and non-medication group for medicines of the therapeutic category with differences in the number of patients was analyzed.

\section{Statistical analysis}

The propensity scores for a target variable were calculated based on a multivariate logistic model using the 7 other variables. For quantitative variables (age, number of medications, stratum corneum moisture content, height, weight, BMI, and thigh circumference), each cutoff value was set by the receiver operating characteristic curve analysis.

The correlation between the number of medications and gait speed was analyzed using the Spearman's rank correlation coefficient. The differences in variables between the two groups were analyzed using the Mann Whitney U test as well as the Fisher's exact test.

All statistical analyses were performed using EZR (Saitama Medical Center, Jichi Medical University, Saitama, Japan, version 1.33), which is a graphical user interface for R (the R Foundation for Statistical Computing, Vienna, Austria, version 3.3.1). More precisely, it is a modified version of the $\mathrm{R}$ commander (version 2.3-0) designed to add statistical functions frequently used in biostatistics [15]. The significance was established when the $p$ value was $<0.05$.

\section{Heat map analysis}

Using Microsoft Excel with the vertical and horizontal axis as patient and therapeutic category number, respectively, a heat map was created by coloring the cells 
with the therapeutic category number of the medicine that each patient was taking. The trends were visually examined by sorting the heat map based on the gait speed of each patient.

\section{Ethical consideration}

This study was approved by the institutional review board of the Suzuka University of Medical Science (Approval No.274, September 5, 2016).

\section{Results}

Participants and propensity score-adjusted multivariate logistic analysis

A total of 31 participants (13 men, 18 women, 79.00 [65.00-89.00] years) was enrolled in the study (Table 1). Propensity score-adjusted multivariate logistic analysis showed that only number of medications was associated with the risk of decreasing gait speed (odds ratio [OR]: 16.00, 95\% confidence interval (CI):1.72-149.00, $p$ value $=0.0149$ ). In contrast, stratum corneum moisture content was not significantly associated with the risk of decreasing gait speed (odds ratio [OR]: 0.362, 95\% confidence interval (CI):0.07-1.88, $p$ value $=0.227$ ) (Table 2). Height, weight and BMI were not analyzed due to lack of freedom. In addition, a negative correlation between the gait speed and number of medications was found (Fig. 1).

\section{Relationship between the gait speed and prescription contents}

As a result of a further analysis, it was found that the proportion of the slow gait speed group patients on 117.Psychotropic agents, 217.Vasodilators, and 333.Anticoagulant tended to be higher (Table 3), therefore we focused among this group on 217.Vasodilators which the group with the largest number of people in the above three groups.

In this therapeutic category, medicines classified as 217.Vasodilators were mainly calcium channel blocker (CCB) such as amlodipine, nifedipine, benidipine, and nitrates. However, the $\mathrm{CCB}$ cilnidipine was classified as 214.Antihypertensives. Therefore, the patients were divided into three groups according to the medicines they took, i.e., CCB, other vasodilators (Remains after removing $\mathrm{CCB}$ from vasodilators), and other antihypertensives (Remains after removing CCB from antihypertensives). In the fast gait speed group there were 6 patients who took CCB (37.50\%), while the slow gait speed group consisted of 13 patients who took CCB (86.67\%). It was shown that the proportion of patients who took CCB in the slow gait speed group was significantly higher than that in the fast gait speed group $(p=0.009)$. Furthermore, by comparing the gait speed for the CCB medication group and non-medication group, it was shown that the gait speed of the medication group was significantly slower than that of the non-medication group (Table 4).

In addition, the $\mathrm{CCB}$ taken by each patient were grouped based on the specific ingredients. Amlodipine, nifedipine, benidipine, cilnidipine were $16,2,1$, and 1 , respectively.

\section{Heat map analysis}

For this study, we focused on 6 or more patients, which was determined to be the average number of patients for each category. When examining the gait speed for the 217.Vasodilators, 232.Agents for peptic ulcer, and 333.Anticoagulants, a tendency was observed that the higher was the decrease in gait speed, the more patients took the medications (Fig. 2).

\section{Discussion}

The results of the statistical analysis carried out in this study showed that a correlation existed between a decreased gait speed and increased number of medications. Subsequently, owing to careful examination and analysis of the prescription contents, it was observed that patients taking CCB had a decreased gait speed. In largescale clinical trials or guidelines for the management of hypertension worldwide, $\mathrm{CCB}$ is regarded as the first choice for hypertension treatments owing to its excellent

Table 1 Patient demographic characteristics $(n=31)$

\begin{tabular}{lll}
\hline Characteristics & Number (\%) or Median [range] & \\
\hline Men & $13(41.93)$ & {$[65.00-89.00]$} \\
Age & 79.00 & {$[0.70-1.54]$} \\
Gait speed (m/s) & 1.02 & {$[5.00-19.00]$} \\
Number of medications & 8.00 & {$[17.00-49.67]$} \\
Stratum corneum moisture content (a.u.) & 33.33 & {$[140.00-169.00]$} \\
Height (cm) & 154.00 & {$[40.00-75.00]$} \\
Weight (kg) & 53.00 & {$[36.00-51.00]$} \\
Thigh circumference $(\mathrm{cm})$ & 43.00 & {$[16.44-27.99]$} \\
BMl & 22.52 & \\
\hline
\end{tabular}


Table 2 Propensity score-adjusted multivariate logistic analysis $(n=31)$

\begin{tabular}{llll}
\hline Risk factors & OR $(95 \% \mathrm{Cl})$ & C statistics & $p$ value \\
\hline Sex & $4.91(0.06-402.00)$ & 0.996 & 0.479 \\
Age & $4.73(0.91-24.50)$ & 0.684 & 0.0643 \\
Number of medications & $16.00(1.72-149.00)$ & 0.794 & 0.0149 \\
Stratum corneum moisture content (a.u.) & $0.362(0.07-1.88)$ & 0.756 & 0.227 \\
Height $(\mathrm{cm})$ & no data & & \\
Weight $(\mathrm{kg})$ & no data & & \\
BMl & no data & 0.982 & 0.955 \\
Thigh circumference $(\mathrm{cm})$ & $0.911(0.04-22.70)$ & \\
\hline
\end{tabular}

antihypertensive effect and safety profile [16-21]. In particular, this drug is widely used because it displays an excellent organ blood flow retention effect and is suitable for cases of organ dysfunction in the elderly [22].

In order to determine the factors associating the use of $\mathrm{CCB}$ with the gait speed, the effect of edema was at first assessed as a common adverse drug reaction of CCB [23]. CCB-induced edema is considered to be caused by fluid extravasation due to the fact that the vasodilatation action of $\mathrm{CCB}$ is larger in the peripheral arteries than in the veins, thus the arterioles expand without vasodilation of the venules, and the capillary pressure rises [24]. The edema may lead to a reduced range of motion [25, 26], as a result of a decrease in the gait speed. This correlates with the patient's complaints of edema.

Experiments that subjected mouse soleus and extensor digitorum longus muscles to continuous stimulation in vitro under $\mathrm{Ca}^{2+}$-free conditions caused a dramatic increase of fatigue in the muscles [27]. CCB are medications used for the treatment of chronic diseases such as hypertension and cardiovascular diseases, and are commonly taken over a long period of time. By blocking for a long period of time the voltage-dependent calcium channels, which are one of the $\mathrm{Ca}^{2+}$ influx pathways to the skeletal muscle, it was assumed that the muscular fatigue would affect the muscle contraction, resulting in a decreased gait speed.

These findings are in agreement with a previous report that polypharmacy significantly increases the risk of frailty in older Japanese adults [28]. A similar study demonstrated that compared with participants taking 0 3 medications, the incidence of frailty was approximately double in those taking 4-6 medications and six times higher in people taking $\geq 7$ medications during an eightyear follow-up [29]. On the other hand, other studies in healthy adults determined that the gait speed is

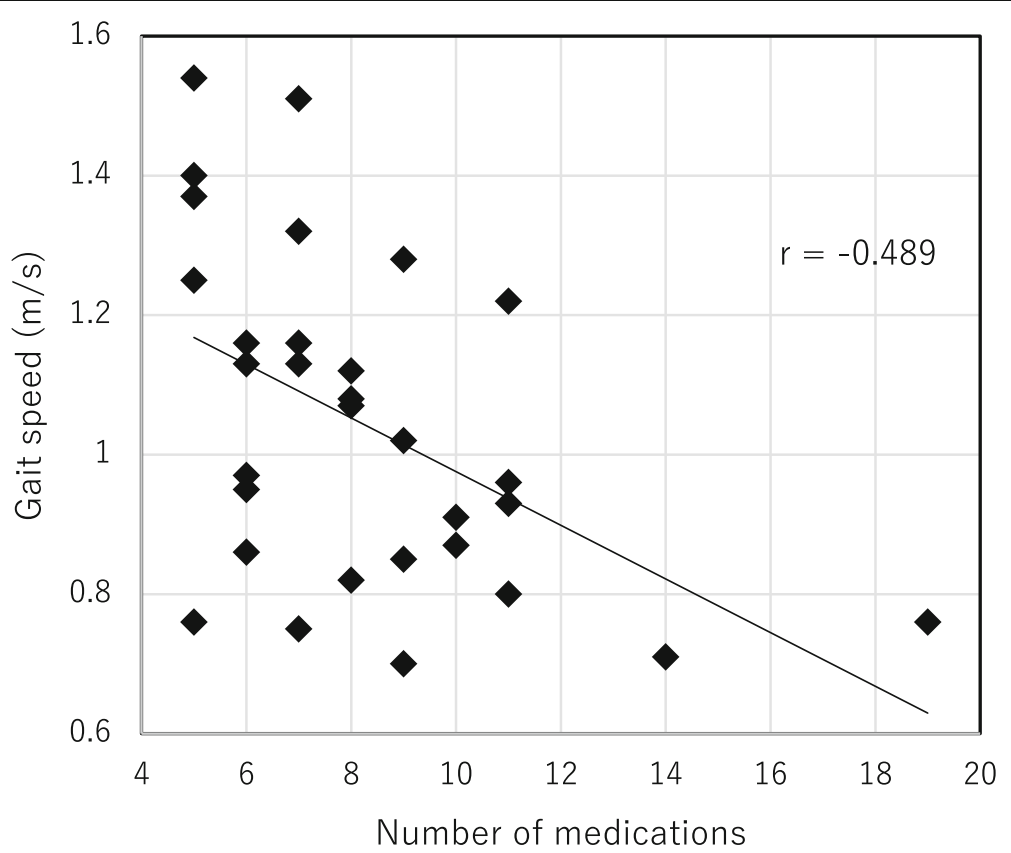

Fig. 1 Correlation between number of medications and gait speed. Examined by the Spearman's correlation coefficient 
Table 3 Number of patients aggregated based on therapeutic category medication

\begin{tabular}{|c|c|c|c|c|c|c|c|c|}
\hline \multirow{2}{*}{$\begin{array}{l}\text { Therapeutic category } \\
\text { number } \\
112\end{array}$} & \multirow{2}{*}{$\begin{array}{l}\text { Name of therapeutic category } \\
\text { Hypnotics and sedatives, antianxietics }\end{array}$} & \multicolumn{2}{|c|}{$\begin{array}{l}\text { All patients } \\
\mathrm{n}=31\end{array}$} & \multicolumn{2}{|c|}{$\begin{array}{l}\text { Fast gait speed } \\
\text { group } n=16\end{array}$} & \multicolumn{2}{|c|}{$\begin{array}{l}\text { Slow gait speed } \\
\text { group } n=15\end{array}$} & \multirow{2}{*}{$\frac{p \text { value }}{0.716}$} \\
\hline & & 11 & $35.48 \%$ & 5 & $31.25 \%$ & 6 & $40.00 \%$ & \\
\hline 113 & Antiepileptics & 1 & $3.23 \%$ & 0 & $0.00 \%$ & 1 & $6.67 \%$ & 0.484 \\
\hline 114 & Antipyretics, analgesics and anti-inflammatory agents & 3 & $9.38 \%$ & 1 & $5.88 \%$ & 2 & $13.33 \%$ & 0.600 \\
\hline 116 & Antiparkinsonism agents & 1 & $3.13 \%$ & 0 & $0.00 \%$ & 1 & $6.67 \%$ & 0.484 \\
\hline 117 & Psycotropic agents & 3 & $9.68 \%$ & 0 & $0.00 \%$ & 3 & $20.00 \%$ & 0.101 \\
\hline 119 & Other agents affecting the central nervous system & 2 & $6.45 \%$ & 0 & $0.00 \%$ & 2 & $13.33 \%$ & 0.226 \\
\hline 124 & Antispasmodics & 1 & $3.23 \%$ & 0 & $0.00 \%$ & 1 & $6.67 \%$ & 0.484 \\
\hline 133 & Antimotionsickness agents & 1 & $3.23 \%$ & 0 & $0.00 \%$ & 1 & $6.67 \%$ & 0.484 \\
\hline 212 & Antiarrhythmic agents & 3 & $9.68 \%$ & 1 & $6.25 \%$ & 2 & $13.33 \%$ & 0.600 \\
\hline 213 & Diuretics & 2 & $6.45 \%$ & 1 & $6.25 \%$ & 1 & $6.67 \%$ & 1.000 \\
\hline 214 & Antihypertensives & 24 & $77.42 \%$ & 14 & $87.50 \%$ & 10 & $66.67 \%$ & 0.220 \\
\hline 217 & Vasodilators & 20 & $64.52 \%$ & 8 & $50.00 \%$ & 12 & $80.00 \%$ & 0.135 \\
\hline 218 & Agents for hyperlipidemias & 22 & $70.97 \%$ & 12 & $75.00 \%$ & 10 & $66.67 \%$ & 0.704 \\
\hline 219 & Other cardiovascular agents & 7 & $22.58 \%$ & 2 & $12.50 \%$ & 5 & $33.33 \%$ & 0.220 \\
\hline 223 & Expectorants & 3 & $9.68 \%$ & 1 & $6.25 \%$ & 2 & $13.33 \%$ & 0.600 \\
\hline 231 & Antidiarrheals, intestinal regulators & 2 & $6.45 \%$ & 1 & $6.25 \%$ & 1 & $6.67 \%$ & 1.000 \\
\hline 232 & Agents for peptic ulcer & 22 & $70.97 \%$ & 10 & $62.50 \%$ & 12 & $80.00 \%$ & 0.433 \\
\hline 233 & Stomachics and digestives & 2 & $6.45 \%$ & 1 & $6.25 \%$ & 1 & $6.67 \%$ & 1.000 \\
\hline 234 & Antiacids & 5 & $16.13 \%$ & 3 & $18.75 \%$ & 2 & $13.33 \%$ & 1.000 \\
\hline 235 & Purgatives and clysters & 5 & $16.13 \%$ & 1 & $6.25 \%$ & 4 & $26.67 \%$ & 0.172 \\
\hline 239 & Other agents affecting digestive organs & 3 & $9.68 \%$ & 1 & $6.25 \%$ & 2 & $13.33 \%$ & 0.600 \\
\hline 259 & Other agents for uro-genital and anal organs & 2 & $6.45 \%$ & 0 & $0.00 \%$ & 2 & $13.33 \%$ & 0.226 \\
\hline 311 & Vitamin A, D and preparations & 6 & $19.35 \%$ & 3 & $18.75 \%$ & 3 & $20.00 \%$ & 1.000 \\
\hline 313 & Vitamin B preparations (except Vitamin B1) & 3 & $9.68 \%$ & 2 & $12.50 \%$ & 1 & $6.67 \%$ & 1.000 \\
\hline 317 & $\begin{array}{l}\text { Mixed vitamin preparations (except mixed vitamin preparations } \\
\text { compounded of vitamin } A \text { and } D \text { ) }\end{array}$ & 2 & $6.45 \%$ & 2 & $12.50 \%$ & 0 & $0.00 \%$ & 0.484 \\
\hline 321 & Calcium compounds and preparations & 1 & $3.23 \%$ & 0 & $0.00 \%$ & 1 & $6.67 \%$ & 0.484 \\
\hline 322 & Mineral preparations & 1 & $3.23 \%$ & 0 & $0.00 \%$ & 1 & $6.67 \%$ & 0.484 \\
\hline 333 & Anticoagulants & 6 & $19.35 \%$ & 1 & $6.25 \%$ & 5 & $33.33 \%$ & 0.083 \\
\hline 339 & Other agents relating to blood and body fluides & 18 & $58.06 \%$ & 8 & $50.00 \%$ & 10 & $66.67 \%$ & 0.473 \\
\hline 392 & Antidotes & 1 & $3.23 \%$ & 1 & $6.25 \%$ & 0 & $0.00 \%$ & 1.000 \\
\hline 394 & Agents for treatment of goat & 5 & $16.13 \%$ & 3 & $18.75 \%$ & 2 & $13.33 \%$ & 1.000 \\
\hline 396 & Antidiabetic agents & 9 & $29.03 \%$ & 6 & $37.50 \%$ & 3 & $20.00 \%$ & 0.433 \\
\hline 399 & Agents affecting metabolism, n.e.c. & 5 & $16.13 \%$ & 3 & $18.75 \%$ & 2 & $13.33 \%$ & 1.000 \\
\hline 449 & Other antiallergic agents & 4 & $12.90 \%$ & 2 & $12.50 \%$ & 2 & $13.33 \%$ & 1.000 \\
\hline 520 & Chinese medicines & 1 & $3.23 \%$ & 1 & $6.25 \%$ & 0 & $0.00 \%$ & 1.000 \\
\hline 614 & $\begin{array}{l}\text { Antibiotic preparations acting mainly on gram-positive bacteria and } \\
\text { mycoplasma }\end{array}$ & 2 & $6.45 \%$ & 0 & $0.00 \%$ & 2 & $13.33 \%$ & 0.226 \\
\hline 622 & Anti-tuberculous agents & 1 & $3.23 \%$ & 0 & $0.00 \%$ & 1 & $6.67 \%$ & 0.484 \\
\hline 624 & Synthetic antibacterials & 1 & $3.23 \%$ & 0 & $0.00 \%$ & 1 & $6.67 \%$ & 0.484 \\
\hline
\end{tabular}

$p$ value based upon Fisher's exact test

associated with age, height, and lower limb muscle strength [30, 31]. Our results, however, indicate an association only between the gait speed and number of medications, most likely due to the differences in the patient characteristics. The participants to the reported study were in fact adults over 20 years, while the 
Table 4 Comparison of the gait speed between non-medication and medication groups

\begin{tabular}{llllll}
\hline & \multicolumn{3}{l}{ Gait speed $(\mathrm{m} / \mathrm{s})$} & & \\
\cline { 2 - 5 } & Non-medication group & & Medication group & \\
\hline CCB & $1.15[0.76-1.54]$ & $n=12$ & $0.93[0.70-1.40]$ & $n=19$ & 0.020 \\
Other antihypertensive & $0.87[0.75-1.54]$ & $n=8$ & $1.12[0.70-1.51]$ & $n=23$ & 0.132 \\
Other vasodilators & $1.00[0.70-1.54]$ & $n=28$ & $1.12[0.85-1.16]$ & $n=3$ & 0.925 \\
\hline
\end{tabular}

Data are expressed as median [minimum-maximum]

$p$ value based upon Mann Whitney $\mathrm{U}$ test

participants in our study were older outpatients over 65 years. In addition, no association was observed between the gait speed and stratum corneum moisture content. There have been reports suggesting that the stratum corneum moisture content and frailty maybe related [14], however their relationship is still unclear and additional work is required for acquiring a better understanding.

Hackett et al. reported that the risk of dementia is elevated in elderly over 60 years with a decreased gait speed [32]. In the present study, no participants were taking medications for dementia. Furthermore, upon confirmation the diagnosis disease to attending physicians, no participant with dementia. Thus, the association between the gait speed and dementia was not considered. Although dementia is the main condition requiring support or longterm care [13] in the elderly, focusing on the gait speed is deemed important to observe its further increase.

In the heat map analysis of the gait speed in the case of 217.Vasodilators, 232.Agents for peptic ulcer, and 333.Anticoagulants, we visually observed a higher tendency for patients taking these medications of having an increasingly slower gait speed. Some of the patients who took CCB and anticoagulants were affected by cardiovascular diseases. In patients with a cardiovascular disease, the risk of frailty increased from 2.7 to 4.1 ; it has been reported that the risk of becoming frailty in the follow-up period of three or more years increased 1.5-fold even if frailty did not exist at the baseline [33]. Thus, some patients who took CCB and anticoagulants were considered affected by frailty owing to the effect of the cardiovascular diseases, which led to a decrease in the gait speed.

The present study has some limitations that need to be considered. First, it was difficult to exclude the potential effects of unknown confounders other than those employed in the present study. Second, patients with dementia such as the Alzheimer's disease were not included in the study as we targeted patients who were able to visit the pharmacy on their own, while patients with Parkinson's disease did not participate since patients with gait disturbance were excluded. Another limitation is that the multivariate logistic regression analysis of height, weight, and BMI could not be carried out due to a lack of freedom. However, no correlation was found with the gait speed for any of the variables, therefore it was assumed that no relationship occurred with the gait




speed. Therefore, to validate our result, a controlled prospective observational study will be required. Recently, there have been many reports about polypharmacy in Japan, and Kojima et al. described that the number of adverse drug reactions increases with an increased number of medications $[4,5]$. In this study, we demonstrated that not only the number of medications should be considered as risk factor but also the prescription contents of the medications taken by older outpatients.

\section{Conclusions}

In older outpatients with a decreasing gait speed, a high rate of CCB intake was observed. It was suggested that not only the number of medications but also the prescription contents could serve as an index to identify patients with a high risk of requiring support or long-term care.

Adverse drug reactions such as edema that can affect the gait speed may be developed upon CCB intake. Furthermore, in patients with edema, the risk of falling increases due to a decrease in the gait speed. By performing a proper prescription proposal, it can be assumed that the pharmacists may contribute to the reduction of the risk of needing support or long-term care required by the elderly.

\section{Abbreviations}

a.u: Arbitrary unit; BMI: Body mass index; CCB: Calcium channel blocker;

$\mathrm{Cl}$ : Confidence interval; OR: Odds ratio

\section{Acknowledgements}

We thank Mr. K Goto for helpful discussion

\section{Authors' contributions}

$\mathrm{KO}$ designed the study. MD contributed to data collection and wrote the initial draft of the manuscript. TE contributed to analysis and interpretation of data, and assisted in the preparation of the manuscript. KN have contributed interpretation, and critically reviewed the manuscript. All authors approved the final version of the manuscript, and agree to be accountable for all aspects of the work in ensuring that questions related to the accuracy or integrity of any part of the work are appropriately investigated and resolved.

\section{Funding}

None.

\section{Availability of data and materials}

The datasets during and/or analysed during the current study available from the corresponding author on reasonable request.

\section{Ethics approval and consent to participate}

All patients provided written informed consent. This study was approved by the institutional review board of the Suzuka University of Medical Science (Approval No.274, September 5, 2016).

\section{Consent for publication}

Not applicable.

\section{Competing interests}

The authors declare that they have no competing interests.

\section{Author details}

'Life Pharmacy, 475-1, Kozubeta, Tsu, Mie 514-0061, Japan. ²Laboratory of Clinical Pharmacology, Graduate School of Pharmaceutical Sciences, Suzuka University of Medical Science, 3500-3 Minamitamagaki, Suzuka, Mie 513-8670, Japan. ${ }^{3}$ Laboratory of Immune Regulation, Graduate School of Pharmaceutical Sciences, Suzuka University of Medical Science, 3500-3
Minamitamagaki, Suzuka, Mie 513-8670, Japan. ${ }^{4}$ Labolatory of Pharmacoinformatics, Department of Pharmaceutical Sciences, Suzuka University of Medical Science, 3500-3 Minamitamagaki, Suzuka, Mie 513-8670, Japan.

Received: 27 September 2019 Accepted: 23 October 2019

Published online: 16 November 2019

\section{References}

1. Statistics Bureau, Ministry of internal affairs and Communications: Population Estimates. 2019 http://www.stat.go.jp/english/data/jinsui/tsuki/index.html Accessed 9 Sept 2019

2. The Japan Geriatrics Society. Guidelines for Medical Treatment and Its Safety in the Elderly 2015. Tokyo: The Japan Geriatrics Society, Medical View Co., Ltd; 2015. p. 12-6. (in Japanese)

3. Fulton MM, Allen ER. Polypharmacy in the elderly: a literature review. J Am Acad Nurse Pract. 2005;17:123-32.

4. Kojima T, Akishita M, Nakamura T, Nomura K, Ogawa S, lijima K, Ouchi Y Polypharmacy as a risk for fall occurrence in geriatric outpatients. Geriatr Gerontol Int. 2012;12:425-30.

5. Kojima T, Akishita M, Kameyama Y, Yamaguchi K, Yamamoto H, Eto M, Ouchi Y. High risk of adverse drug reactions in elderly patients taking six or more drugs: analysis of inpatient database. Geriatr Gerontol Int. 2012;12:761-2.

6. Fried LP, Tangen CM, Walston J, Newman AB, Hirsch C, Gottdiener J, Seeman T, Tracy R, Kop WJ, Burke G, McBurnie MA. Frailty in older adults: evidence for a phenotype. J Gerontol A Biol Sci Med Sci. 2001;56:M146-56.

7. The Japan Geriatrics Society: Statement on the frailty from the Japan Geriatrics Society. 2014 http://www.jpn-geriat-soc.or.jp/info/topics/pdf/2014 0513_01_01.pdf Accessed 24 Sept 2019. (in Japanese).

8. Viccaro $L$, Perera S, Studenski SA. Is timed up and go better than gait speed in predicting health, function, and falls in older adults? J Am Geriatr Soc. 2011;59:887-92.

9. Smeesters C, Hayes WC, McMahon TA. Disturbance type and gait speed affect fall direction and impact location. J Biomech. 2001:34:309-17.

10. Dargent-Molina P, Schott AM, Hans D, Favier F, Grandjean H, Baudoin C. Separate and combined value of bone mass and gait speed measurements in screening for hip fracture risk: results from the EPIDOS study. Epidémiol de l'Ostéoporose Osteoporos Int. 1999;9:188-92.

11. Dargent-Molina P, Favier F, Grandjean H, Baudoin C, Schott AM, Hausherr E. Fall-related factors and risk of hip fracture: the EPIDOS prospective study. Lancet. 1996;348:145-9.

12. Ministry of Health, Labour and Welfare: Summary Report of Comprehensive Survey of Living Conditions 2016. 2017 https:/www.mhlw.go.jp/english/ database/db-hss/dl/report_gaikyo_2016.pdf Accessed 24 Sept 2019.

13. lizaka S. Frailty and body mass index are associated with biophysical properties of the skin in community-dwelling older adults. J Tissue Viability. 2018;27:141-5.

14. Ministry of Health, Labour and Welfare: Therapeutic category.2009 https:// www.mhlw.go.jp/shingi/2009/11/dl/s1106-11v.pdf Accessed 24 Sept 2019. (in Japanese).

15. Kanda Y. Investigation of the freely available easy-to-use software 'EZR' for medical statistics. Bone Marrow Transplant. 2013;48:452-8.

16. Go AS, Bauman MA, Coleman King SM, Fonarow GC, Lawrence W, Williams KA, Sanchez E. An effective approach to high blood pressure control: a science advisory from the American Heart Association, the American College of Cardiology, and the Centers for Disease Control and Prevention. J Am Coll Cardiol. 2014;63:1230-8.

17. James PA, Oparil S, Carter BL, Cushman WC, Dennison-Himmelfarb C, Handler J, Lackland DT, LeFevre ML, MacKenzie TD, Ogedegbe O, Smith SC Jr, Svetkey LP, Taler SJ, Townsend RR, Wright JT Jr, Narva AS, Ortiz E. 2014 evidence-based guideline for the management of high blood pressure in adults: report from the panel members appointed to the eighth joint National Committee (JNC 8). JAMA. 2014;311:507-20

18. Mancia G, Fagard R, Narkiewicz K, Redon J, Zanchetti A, Böhm M, Christiaens T, Cifkova R, De Backer G, Dominiczak A, Galderisi M, Grobbee DE, Jaarsma T, Kirchhof P, Kjeldsen SE, Laurent S, Manolis AJ, Nilsson PM, Ruilope LM, Schmieder RE, Sirnes PA, Sleight P, Viigimaa M, Waeber B, Zannad F, Members TF. 2013 ESH/ESC guidelines for the management of arterial hypertension: the task force for the management of arterial 
hypertension of the European Society of Hypertension (ESH) and of the European Society of Cardiology (ESC). J Hypertens. 2013;31:1281-357.

19. The National Institute for Health and Care Excellence: Hypertension in adults: diagnosis and management. 2011 https://www.nice.org.uk/guidance/ cg127 Accessed 24 Sept 2019.

20. Qaseem A, Wilt TJ, Rich R, Humphrey LL, Frost J, Forciea MA. Pharmacologic treatment of hypertension in adults aged 60 years or older to higher versus lower blood pressure targets: a clinical practice guideline from the American College of Physicians and the American Academy of family physicians. Ann Intern Med. 2017;166:430-7.

21. Weber MA, Schiffrin EL, White WB, Mann S, Lindholm LH, Kenerson JG, Flack JM, Carter BL, Materson BJ, Ram CV, Cohen DL, Cadet JC, Jean-Charles RR, Taler S, Kountz D, Townsend RR, Chalmers J, Ramirez AJ, Bakris GL, Wang J, Schutte AE, Bisognano JD, Touyz RM, Sica D, Harrap SB. Clinical practice guidelines for the management of hypertension in the community: a statement by the American Society of Hypertension and the International Society of Hypertension. J Clin Hypertens. 2014;16:14-26.

22. Shimamoto K, Ando K, Fujita T, Hasebe N, Higaki J, Horiuchi M, Imai Y, Imaizumi T, Ishimitsu T, Ito M, Ito S, Itoh H, Iwao H, Kai H, Kario K, Kashihara N, Kawano Y, Kim-Mitsuyama S, Kimura G, Kohara K, Komuro I, Kumagai H, Matsuura H, Miura K, Morishita R, Naruse M, Node K, Ohya Y, Rakugi H, Saito I, Saitoh S, Shimada K, Shimosawa T, Suzuki H, Tamura K, Tanahashi N, Tsuchihashi T, Uchiyama M, Ueda S, Umemura S. The Japanese Society of Hypertension Guidelines for the Management of Hypertension (JSH 2014). Hypertens Res. 2014;37:253-390.

23. Papavassiliou MV, Vyssoulis GP, Karpanou EA, Belegrinos DA, Giannakopoulou AE, Toutouzas PK. P-256: side effects of antihypertensive treatment with calcium channel antagonists. Am J Hypertens. 2001;14:114A.

24. De la Sierra A. Mitigation of calcium channel blocker-related oedema in hypertension by antagonists of the renin-angiotensin system. J Hum Hypertens. 2009;23:503-11.

25. Gajdosik RL, Bohannon RW. Clinical measurement of range of motion. Review of goniometry emphasizing reliability and validity. Phys Ther. 1987;67:1867-72.

26. Back TL, Padberg FT Jr, Araki CT, Thompson PN, Hobson RW. Limited range of motion is a significant factor in venous ulceration. J Vasc Surg. 1995;22:519-23.

27. Germinario E, Esposito A, Midrio M, Peron S, Palade PT, Betto R, DanieliBetto D. High-frequency fatigue of skeletal muscle: role of extracellular Ca(2+). Eur J Appl Physiol. 2008;104:445-53.

28. Yuki A, Otsuka R, Tange C, Nishita Y, Tomida M, Ando F, Shimokata H. Polypharmacy is associated with frailty in Japanese community-dwelling older adults. Geriatr Gerontol Int. 2018;20:1497-500.

29. Veronese N, Stubbs B, Noale M, Solmi M, Pilotto A, Vaona A, Demurtas J, Mueller C, Huntley J, Crepaldi G, Maggi S. Polypharmacy is associated with higher frailty risk in older people: an 8-year longitudinal cohort study. J Am Med Dir Assoc. 2017;18:624-8.

30. Himann JE, Cunningham DA, Rechnitzer PA, Paterson DH. Age-related changes in speed of walking. Med Sci Sports Exerc. 1988;20:161-6.

31. Kim JD, Kuno S, Soma R, Masuda K, Ishizu M, Adachi T, Nishiijma T, Okada M. Relationship between reduction of hip joint and thigh muscle and walking ability in elderly people. Jpn J Phys Fitness Sports Med. 2000;49: 589-96 (in Japanese).

32. Hackett RA, Davies-Kershaw H, Cadar D, Orrell M, Steptoe A. Walking speed, cognitive function, and dementia risk in the English longitudinal study of ageing. J Am Geriatr Soc. 2018;66:1670-5.

33. Afilalo J, Karunananthan S, Eisenberg MJ, Alexander KP, Bergman H. Role of frailty in patients with cardiovascular disease. Am J Cardiol. 2009;103:1616-21.

\section{Publisher's Note}

Springer Nature remains neutral with regard to jurisdictional claims in published maps and institutional affiliations.

Ready to submit your research? Choose BMC and benefit from:

- fast, convenient online submission

- thorough peer review by experienced researchers in your field

- rapid publication on acceptance

- support for research data, including large and complex data types

- gold Open Access which fosters wider collaboration and increased citations

- maximum visibility for your research: over $100 \mathrm{M}$ website views per year

At BMC, research is always in progress.

Learn more biomedcentral.com/submissions 